\title{
OS PIGMENTOS AMARELO-LARANJA DO GRÃO DE MILHO COMO PRECURSORES DA VITAMINA A NA ALIMENTAÇÃO DOS PINTOS *
}

\author{
E. A. Graner e A. P. Torres \\ Escola Superior de Agricultura "Luiz de Queiroz" \\ Universidade de Săo Paulo
}

\section{INDICE}

1) INTRODUÇA ......290

2) MAT́TERIAL E METODO 290

3) EXPERIMENTAL ..... 291

a) Quantidade de pigmentos das variedades com grãos caloridos 291

b) Análises dos lotes de pintos no início da experiéncia .......293

c) Lote $\mathbf{B}$ (milho branco "Cristal") .......293 d) Lote A (Milho Iaranja-forte "Cateto") e Lote C (Milho amarelo-l a $r$ an ja "Armour") ..........298

4) RESUMO E CONCLUSOES $\ldots \ldots \ldots \ldots \ldots \ldots, 303$

5) AGRADECIMENTOS . . 303

6) ABSTRACT ........ 304

7) BIBLIOGRAFIA ...... 304

* Trabalho da Seção de Avicultura e Cunicultura. 


\section{1) INTRODUÇAO}

A importancia das vitaminas no desenvolvimento dos animais é um problema que tem recebido a atenção de muitos pesquisadores e a influencia benéfica delas no crescimento dos pintos, principalmente da vitamina $A$, é um assunto bem conhecido e nåo precisa ser aqui discutido. Diversos autores demonstraram que săo necessárias de 150 a 200 unidades U. S. P. de vitamina A, pelo menos, para promover um crescimento normal. (16). Muitas săo as fontes de vitamina A para o organismo, seja na sua forma natural ou seja como pró-vitamina. Dentre as fontes de pró-vitamina destacam-se, como importantes para nós, os grãos de mil ho de coloraçáo amarela ou amarelo-laranja os quais possuem dois pigmentos precursores de vitamina $A, 0 \quad \beta$ caroteno e a criptoxantina. Um dos autores déste trabalho (GRANER) tem se ocupado com o estudo da genética dessa coloraçáo amarelo-laranja dos grăos de milho e, no presente, apresentamos os resultados obtidos numa experiéncia organizada para se constatar a influência de variedades comerciais, típicas e comuns no pais, que apresentam variaçáo na intensidade de coloraçăo dos gráos, como fornecedoras de pró-vitamina A na raçăo.

\section{2) MATERIAL E METODO}

Duas variedades de milho com grăos coloridos foram utilizadas na presente experiêncla : o milho dente chamado "Armour", cujos grãos têm uma coloração amarelo-laranja e o milho duro chamado "Cateto", com grãos coloridos de laranja-forte. Para testemunha empregámos o milho "Cristal", cujos grăos duros são completamente desprovidos de qualquer pigmento do grupo carotenóide. Esses três tipos de milho sáo os mesmos já utilizados numa outra experiencia sóbre a coloraçáo da gema de ôvo de galinha (9). Os grăos desses três tipos de milho, depois de moidos, entraram na ração como $\mathbf{7 0 \%}$ do seu volume, tendo sido escolhida uma fórmula que elimlnasse tanto quanto possivel, qualquer outra fonte de vitamina A ou pró-vitamina A. A ração utilizada tinha assim a seguinte composiça: : 


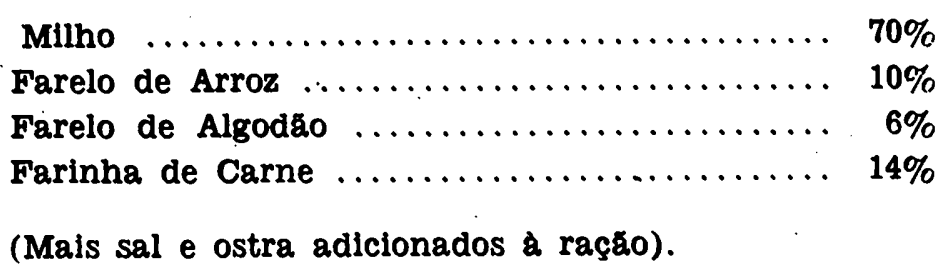

Tres raçōes foram preparadas, designadas, A, B, e C e contendo respectivamente milho "Cateto", "Cristal" e "Armour". Correspondendo aos três tipos de raçăo, foram organizados três lotes de pintos da raça "Rhode Island Red" de três semanas de idade. Os pintos para cada um dos três grupos foram tirados ao acaso de um lote bastante grande, tendo sido feito uma tentativa de seleção em favor das femeas. Devido a certas dificuldades na classificaçáo do sexo quando ainda pequenos, alguns machos passaram a fazer parte de cada grupo e os resultados obtidos com relaçáo a influencia do sexo são mencionados adiante. Os pintos foram numerados individualmente, tendo sido feita uma pesagem inicial de cada um deles e outras pesagens semanais, durante um periodo de seis semanas. Durante todo o tempo da experiencia as pintos foram mantidos em gaiolas especiais, que recebiam diariamente uma exposiçáo de sol. Para comparaçăo, as rações A e B foram dadas também a dois lotes de pintos de 5 dias, cada lote sendo formado de 10 pintos, também pesados semanalmente.

\section{3) EXPERIMENTAL}

Os dados obtidos na presente experiéncia serão apresentados por partes, como segue.

a) Quantidade de pigmentos das variedades com grăos coloridos.

Uma análise da quantidade de pigmentos do grupo carotinólde para as dois tipas de milho estudados fol realizada, estando os dados reunidos no quadro N.O 1 
O método empregado permite uma observação da quantidade total de pigmentos e da quantidade da parte mais importante, chamada ativa, em relação à formação da Vitamina A no organismo animal, por conter os pigmentos $\beta$ carote-

\section{QUADRO N.0 1}

\begin{tabular}{|l|c|c|c|}
\hline \multirow{3}{*}{ Variedade } & Côr da & $\begin{array}{c}\text { Carotenóides } \\
\text { por grama de farinha }\end{array}$ \\
\cline { 1 - 1 } & semente & Total & $\beta-\begin{array}{c}\text { caroteno }+ \text { crip- } \\
\text { toxantina } \\
\text { (Pró-Vitamina A) }\end{array}$ \\
\hline Cateto & $\begin{array}{c}\text { Laranja } \\
\text { forte } \\
\text { Amarelo- } \\
\text { laranja }\end{array}$ & 0,0450 & 0,0207 \\
\hline Armour & 0,0253 & 0,0120 \\
\hline
\end{tabular}

no e criptoxantina. Déstes dois pigmentos ativos, o mais importante é o primeiro, pois cada molécula se desdobra no organismo animal em duas moléculas de vitamina A (Vela a ilustração anexa). Pelos números obtidos podemos verificar que a dife-<smiles></smiles><smiles>C/C=C(C)\C=C\C=C(C)\C=C\C1=C(C)CCCC1(C)C</smiles>

rença na tonalidade da coloração dos grãos corresponde uma diferença no conteudo dos pigmentos, possuindo o milho " $\mathrm{Ca}$ tcto" pràtiçamente Q dóbro em relação ao milho "Armour". 
Assim, o milho "Cateto", com grãos laranja forte, tem uma potencialidade pro-vitaminica dobrada em relaçăo ao milho "Armour", de gráos amarelo-laranja.

b) Análise dos lotes no início da experiencia.

Após a separação dos três lotes de pintos da Raça "Rhode Island Red", felta ao acaso, foram esses pintos pesados e determinada a média para cada um dos lotes. Tendo havido uma diferença numérica para os valores das tres médias, foi feita pelo teste $t$ uma análise para verificar se essa diferença era estatisticamente importante ou năo.

\section{QUADRO N.0 2}

\begin{tabular}{|c|c|c|c|}
\hline \multicolumn{3}{|c|}{ Pesagem inicial } \\
\hline Lote & $\bar{v}$ & $\pm \sigma$ & $n$ \\
\hline $\mathrm{A}$ & 141,93 & 13,50 & 20 \\
$\mathrm{~B}$ & 149,43 & 17,55 & 20 \\
$\mathrm{C}$ & 143,65 & 18,68 & 20 \\
\hline $\mathrm{t} A / \mathrm{B}=-1,51$ & (Insignificante) \\
$\mathrm{t} \mathrm{C} / \mathrm{B}=-1,01$ & (Insignificante) \\
$\mathrm{t} \Lambda / \mathrm{C}=-\mathbf{0 , 3 3}$ & (Insignificante) \\
\hline
\end{tabular}

Os dadas obtidos estão reunidos no quadro N.० 2 , onde se constata, pelos valores insignificantes de $t$, que os tres lotes apresentaram apenas diferenças devidas ao acaso, sendo portanto práticamente uniformes.

c) Lote B (Milho branco, "Cristal")

Durante as duas primeiras semanas da experiencia todas os tres lotes de pintos reagiram pràticamente da mesma maneira. 


\begin{tabular}{|c|c|c|c|c|c|c|c|c|}
\hline \multirow{2}{*}{\multicolumn{2}{|c|}{$\begin{array}{c}\text { Lote } \mathbf{B} \\
\text { n. }{ }^{\circ} \text { do pinto }\end{array}$}} & \multicolumn{6}{|c|}{ Ganho em pêso (grs.) por semana } & \multirow{2}{*}{$\begin{array}{l}\text { Aspeto geral } \\
\text { após } 6 \text { se- } \\
\text { manas de } \\
\text { tratamento }\end{array}$} \\
\hline & & 1.a & 2.a & 3.a & $4 . a$ & 5.2 & 6.a & \\
\hline & 301 & 50,5 & 51,0 & 19,0 & - & - & - & - \\
\hline & 302 & 67,5 & 75,5 & 81,0 & 98,0 & 51,0 & $-38,0$ & Ruim \\
\hline & 303 & 62,5 & 90,5 & 69,0 & $-20,0$ & 43,0 & - & - \\
\hline & 304 & 29,5 & 57,0 & 19.0 & 0 & 24,0 & $-74,0$ & Ruim \\
\hline & 305 & 43,5 & 70,0 & 79,0 & 90,0 & 110,0 & $-117,0$ & Ruim \\
\hline & 306 & 71,5 & 94,0 & 57,0 & $-11,0$ & 77,0 & - & - \\
\hline & 307 & 65,0 & 70,5 & 85,0 & 51.0 & 84,0 & 45,0 & Bom \\
\hline & 308 & 66,5 & 75,0 & 46,0 & $-45,0$ & - & - & - \\
\hline & 309 & 51.0 & 54,0 & 35,0 & 1.0 & 16,0 & - & - \\
\hline & 310 & 35,0 & 14,0 & 0 & - & - & - & - \\
\hline & 311 & 65,0 & 95,0 & 5.0 & - & - & - & - \\
\hline & 312 & 53,0 & 84,0 & 63,0 & 33,0 & $-106,0$ & - & - \\
\hline & 313 & $\mathbf{4 7 , 5}$ & 68,0 & 69,0 & $-72,0$ & - & - & - \\
\hline & 314 & 59,5 & 78,0 & 33,0 & -55.0 & - & - & - \\
\hline & 315 & 51,0 & 67,0 & 58,0 & 26,0 & 42,0 & -3.0 & Regular \\
\hline & 316 & 37,0 & 56,0 & 68,0 & 45.0 & 63,0 & 5,0 & Regular \\
\hline & 317 & 60,0 & 74,5 & 28,0 & $-38,0$ & - & - & - \\
\hline & 318 & 42,0 & 34,0 & 38,0 & - & - & - & - \\
\hline & 319 & 60,0 & 58,0 & 14,0 & - & - & - & - \\
\hline & 320 & 56,0 & 67,0 & 0 & 20,0 & 一 & - & - \\
\hline \multicolumn{2}{|l|}{ Total } & 1073,0 & 1333,0 & 866,0 & 123,0 & 404,0 & $-182,0$ & - \\
\hline \multicolumn{2}{|l|}{$\mathbf{n}$} & 20 & 20 & 20 & 15 & 10 & 6 & 6 \\
\hline \multicolumn{2}{|c|}{ Média } & 53,65 & 66,65 & 43,30 & 8,78 & 40,40 & $-30,33$ & - \\
\hline
\end{tabular}


O lote $B$, que era o que levava uma pequena vantagem, no pêso iniclal, manteve essa diferença durante as duas primelras semanas, igualando, porém, no fim da terceira semana, seu pêso médio com aquêle dos lotes A e C. (Compare a par-

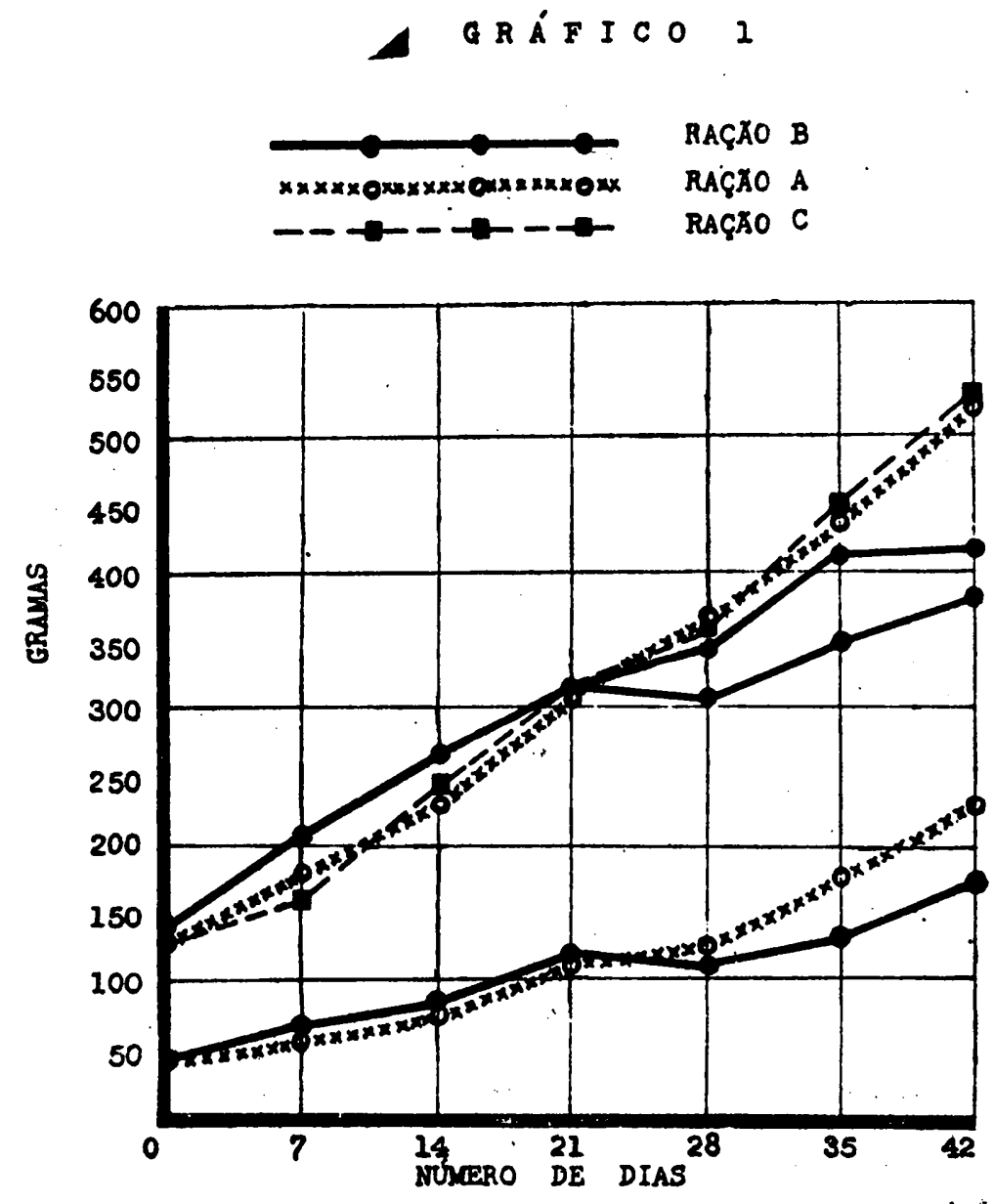

te de cima do gráfico 1). Também, no caso de pintos com apenas cinco dias, a reação fol a mesma, como se constata na parte de baixo do gráfico 1. Da quarta semana em diante as difercnças do lote $\mathbf{B}$ com relação a $\mathbf{A}$ e $\mathbf{C}$ se acentuaram tanto que Justificaram uma análise separada em dois grupos distin- 
tos, ou seja o grupo com a raçăo B e o grupo formado pelos do:s lotes com as raçóes $\mathrm{A}$ e C. Os dados detalhados para o lote $B$ estão reunidos no quadro N.o 3. São 20 pintos, numerados individualmente e cujos números estão contidos na primeira coluna do referido quadro. As seis colunas seguintes contêm o ganho médio em gramas para cada pinto, em seis semanas seguidas. A última coluna contém as informaçóes sóbre os animais após a 6.a semana, quando a experiéncia foi terminada. Na parte de baixo do mesmo quadro estão contidos os números de pintos bem como o ganho médio de todos êles em cada semana. O ganho médio de 20 pintos nas duas primeiras semanas, para o lote $B$, foi um pouco superior àquele obtido pelos pintos dos lotes A e C (Compare os quadros N. ${ }^{\circ}$ 3 e 5) mas essa diferença deve ter sido devida a vantagem inicial do lote B. Comparando-se as colunas das duas primeiras semanas para o lote $B$, quadro 3 , constata-se que cada pinto reagiu favoràvelmente nesse perfodo, cada um dêles tendo tido um aumento de péso bastante razoável. Já na terceira semana observa-se uma queda bastante grande da média dos 20 pintos com a ração $B$ em comparação aqueles que receberam as rações $A$ e C. Examinando os pintos individualmente para o caso do lote $B$, vamos constatar uma reação bastante diferente para cada um dêles. Enquanto que alguns continuaram a aumentar normalmente de péso, outros obtiveram um ganho muito pequeno. (Nos. 301, 304, 311 e 319) e outros ainda não aumentaram de pêso. (Nos. 310 e 320). Da quarta semana em diante, então as diferenças săo muito grandes, năo havendo mais necessidade de comparação do lote $B$ para com os lotes A e C. A diferença entre os pintos do lote B é, porém, bastante apreciável, uns continuando ainda na quarta semana a ter um aumento normal de pêso, enquanto os outros começaram a perder pêso, alguns menos e outros mais, cinco déles tendo morrido. Na quinta semana restavam apenas 10 pintos, dos quais sete continuaram a aumentar normalmente de pêso, do's tiveram um aumento muito pequeno (Nos. 304 e 309) e um dêles; (No. 312) teve uma perda considerável de pêso. $\mathrm{Na}$ 'sexta semana so restava um pinto (N.o 307), que aind? continuou aumentando de pêso, embora êsse aumento tivesse sido a metade daquele obtido da 5.a semana. Nesta semana, isto é, na 6.a, restavam apenas 6 pintos, dos quais 4 tiveram perda de pêso e um só teve um ganho de 5 gramas. Após a $6 . a$ remana de tratamento, a experiência foi terminada, pois só restava um pinto em condiçóes mais ou menos satisfatórias, mas que seria por certo eliminado também depois de mais alcum tempo de tratamento, tratando-se possivelmente de um 
animal um pouco mais resistente que os outros. Aquêles pintos; que, após a 6.a semana ainda não tinham morrido, apresentavam-se com um aspeto bastante ruim, caminhando ràpidamente para a morte. $O$ quadro N. 4 resume o número de $\mathrm{p}: \mathrm{n}$ tos mortos em cada semana de tratamento.

\section{QUADRO N.O 4}

\begin{tabular}{|c|c|c|c|c|c|c|}
\hline Lote $\mathbf{B}$ & \multicolumn{6}{|c|}{$\begin{array}{l}\text { Pintos mortos durante } 6 \\
\text { semanas de tratamento }\end{array}$} \\
\hline Semanas & $1 . \mathrm{a}$ & $2 . a$ & 3.a & $4 . a$ & 5.2 & e a \\
\hline N. ${ }^{\circ}$ de pintos! & 0 & 0 & 0 & 5 & 5 & 4 \\
\hline
\end{tabular}

Os pintos do lote $B$, quando começavam a perder o péso, apresentavam secreçăo mucosa, tristeza, marcha dificil, ai azas e pescoço caidos (observe a figura inclusa) e não se allmentavam mals. Todos os pintos, que morreram, foram necropsiados, tendo sido constatado nos seus orgáos internos o seguinte :

Pericardio : inflamado

Coraçăo : coágulos sanguíneos

Vesicula billiar: volumosa e endurecida

Moela : muito inflamada

Rins : depósitos de urato

Pulmóes : congestionados

Esôfago: granulaçరes amareladas, parede espêssa.

No gráfico 1, estão reunidas as médias do ganho em pêso para cada um dos três lotes e para cada semana. A linha cheia representa o lote com a ração $B$ (milho branco) e na quarta semana observa-se uma queda bastante grande de peso para êste grupo, enquanto que os dols outros grupos (raçoes A e C) continuam sempre a aumentar de pesso. As duas linhas cheiari após a 3.a semana representam: a inferior, as médias dor pintos inclusive aqueles mortos durante a semana e a superior, as médias obtidas sòmente dos pintos ainda vivos. A ascenção que se nota após a 4.a semana, para éste lote, é devida a alimento verde (folhas de repolho) dado aos pintos uma ún1- 
ca vez. Assim, observa-se que, quando começam a sentir o efeito do tratamento, pequena quantidade de verdura traz uma reação forte e rápida no desenvolvimento dos animais. Na parte de baixo do gráfico 1 estão as médias para os lotes A e B com pintos de 5 dias e por onde se vê que a reação se inicia sempre após as três primeiras semanas de tratamento.

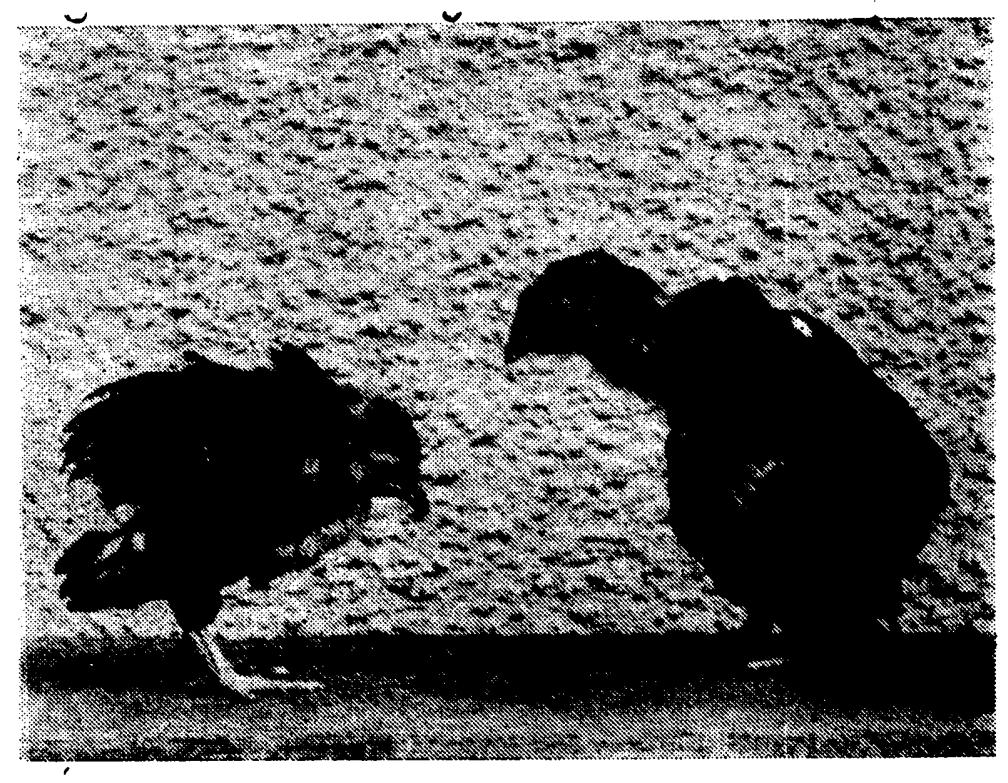

Pintos submetidos durante 4 semanas a uma alimentação deficiente em Vitamina A. A ração foi composta de Milho Branco Cristal em lugar de milho amarelo fornecedor de pigmentos precursores dessa vitamina no organismo animal.

d) Lote A (Milho laranja-forte "Cateto") e Lote C (Milh J amarelo-laranja "Armour").

Estes dois lotes reagiram pràticamente da mesma manei$\mathrm{ra}$, apesar de que o lote $\mathrm{A}$ recebesse uma ração contendo o $\mathrm{mi}$ lho "Cateto" e porisso uma quantidade de pigmentos pró-vitamínicos dobrada com relação ao lote $\mathrm{C}$, em regime de milho "Armour". O gráfico 1 mostra, na linha interrompida e na linha formada por cruzes, as curvas obtidas para estas duas rações. Observa-se, por elas, que os pintos que receberam estas duas rações, nas seis semanas da experiência, não apresentaram diferenças importantes. 
QUADRO N. 5

\begin{tabular}{|c|c|c|c|c|c|c|c|c|c|}
\hline \multicolumn{10}{|c|}{ Ganho em péso (média em grs.) } \\
\hline \multirow{2}{*}{ Sexo } & \multirow{2}{*}{ Lote } & \multirow{2}{*}{ N. ${ }^{\circ}$} & \multicolumn{4}{|c|}{ Semanas } & \multicolumn{2}{|c|}{. } & \multirow{2}{*}{ Total } \\
\hline & & & $1 . a$ & $2 . a$ & 3.a & $4 . a$ & 5.a & 6.a & \\
\hline \multirow{2}{*}{ Fêmea } & $\mathbf{A}$ & 13 & 40,38 & 49,69 & 62,38 & 46,92 & 65,53 & 65,00 & 54,96 \\
\hline & $\mathbf{c}$ & 15 & 44,10 & 51,10 & $=5,67$ & 51,13 & 75,60 & 77,06 & 59,11 \\
\hline \multirow{4}{*}{ Macho } & Total & 28 & 42,24 & 50,39 & 59,02 & $\leq 9,02$ & 70,56 & 71,03 & 57,03 \\
\hline & $\mathbf{A}$ & 7 & 50,00 & 63,78 & $\mathbf{7 4 , 7 1}$ & $\mathfrak{E 9 , 8 6}$ & 90,28 & 99,00 & 74,60 \\
\hline & C & 5 & 44,00 & 68,00 & 67,23 & 70,40 & 93,80 & 108,40 & 74,96 \\
\hline & Total & 12 & 47,00 & 65,89 & $7 €, 85$ & 70,13 & 92,04 & $102, \pi 0$ & 74,78 \\
\hline
\end{tabular}


Na sexta semana da experiência foi possivel separar o sexo dos animais dêstes lotes e assim verificámos que, apesar de ter sido feita uma seleção em favor das fêmeas, no início apareceu ainda um certo número de machos, cuja reação fol bastante diferente daquela das fêmeas. Uma comparação entre os dois lotes A e C e também entre os dois sexos foi feita, estando os dados reunidos no quadro N.0 5. Por êste quadro verifica-se que os machos têm um aumento médio por semana bastante superior ao das fêmeas e as diferenças entre o ganho da fêmea e aquêle do macho, no total, são estatisticamente significativas para o caso do lote A e para o total, sendo duvidosa para o lote $\mathbf{C}$, conforme os testes reunidos no quadro N. ${ }^{0}$.

\section{QUADRO N. 6}

\begin{tabular}{|cc|}
\hline & Entre sexo \\
\hline Lote A & t fêmea $/$ macho $=-5,52$ (Significante) \\
Lote C & t fêmea $/$ macho $=-2,26$ (Duvidoso) \\
Total & t fêmea $/$ macho $=-5,53$ (Significante) \\
\hline
\end{tabular}

Podemos assim coñcluir que os machos têm um aumento médio maior que as fêmeas, não só no total das seis semanas como também, de uma forma geral, em cada uma das seis semanas de tratamento o que, aliás, tem sido constatado por outros. Observando-se agora os aumentos médios em cada uma das semanas, tanto para machos como pära fêmeas, vamos notar que há uma diferença da primeira semana para a segunda, ou seja, úm ganho médio de pêso maior na segunda semana em relação ao ganho da primeira semana e que nas três semanas seguintes (2.a, 3.a e 4.a) o ganho médio é, de; uma maneira geral, pràticamente o mesmo. A diferença da 4.a para a $5 . a$ semana é porém bastante grande, tanto para os dois lotes como para os dois sexos. O ganho médio na 6.a semana é idêntico àquele da 5 .a semana, conforme os testes realizados e reunidos no quadro N.O 7.

Assim, o ganho médio em pêso, por semana, é diferente, sendo muito maior nas duas últimas semanas do que nas quatro semanas anteriores. Nestas, a primeira semana tem um aumen- 


\section{QUADRO N.0 7}

\begin{tabular}{|c|}
\hline Entre 5.a e 6.a semanas \\
\hline Lote A fêmea t 5.a/6.a $=+0,09$ \\
Lote A macho t $5 . \mathrm{a} / 6 . \mathrm{a}=-1,53$ \\
Lote C fêmea t $5 . \mathrm{a} / 6 . \mathrm{a}=-0,23$ \\
Lote C macho t $5 . \mathrm{C} / 6 . \mathrm{a}=-0,54$ \\
(Todos valores de $\mathrm{t}$ insignificantes)
\end{tabular}

to médio menor do que aquêle das três semanas seguintes. As differenças entre os dois lotes A e C, na 5.a e 6.a semanas, que apresentaram um aumento médio de péso muito maior que as demais semanas, são insignificantes tomo se pode constatar pelo quadro N.o 8. Podemos então concluir que as diferen-

\section{QUADRO N.0 8}

\begin{tabular}{|c|}
\hline Entre Lotes $\mathrm{A}$ e $\mathrm{C}$ \\
\hline Fémea 5.a semana t $\mathrm{A} / \mathrm{C}=-1,50$ \\
Fémea 6.a semana t $\mathrm{A} / \mathrm{C}=-1,90$ \\
Macho 5.a semana t $\mathrm{A} / \mathrm{C}=-0,28$ \\
Macho 6.a semana t $\mathrm{A} / \mathrm{C}=-0,36$ \\
(Todos valores de $\mathrm{t}$ insignificantes) \\
\hline
\end{tabular}

ças significativas se encontram entre as semanas e entre os sexas, os dois lotes comportando-se igualmente com relação aos dois tipas de alimentaçáo recebidos, uma com milho "Cateto" e outra com milho "Armour".

Uma análise mais detalhada, cujos dados estáo contidos no quadro, 9, confirma estas conclusōes, mostrando ainda que, tanto no grupo das fêmeas como no grupo dos machos, há variação significativa também entre individuos e o que se pode esperar do material utilizado, que năo era formado de linhagens, mas sim de uma população pura para determinados caracteres da raça e heterozigota para muitos outros fatores genéticos. 
QUADRO N.0 9

\begin{tabular}{|c|c|c|c|c|c|c|c|}
\hline \multirow{2}{*}{ Sexo } & \multirow{2}{*}{ Efeito } & \multirow{2}{*}{$\begin{array}{l}\text { Soma dos } \\
\text { quadrados }\end{array}$} & \multirow{2}{*}{$\begin{array}{l}\text { Grau de } \\
\text { liberdade }\end{array}$} & \multirow{2}{*}{$\pm \sigma$} & \multirow{2}{*}{$\imath^{\prime}$} & \multicolumn{2}{|c|}{ Limites de significância } \\
\hline & & & & & & $5 \%$ & $1 \%$ \\
\hline \multirow{5}{*}{ Fêmea } & Total & 24892,68 & 111 & 11.47 & - & - & - \\
\hline & Entre Pintos & 10075,41 & 27 & 19,31 & 1,65 & 1,0 & 1,0 \\
\hline & Entre Semanas & 3809,33 & 3 & 35,64 & 3,04 & 1,6 & 1,9 \\
\hline & Entre Tratamentos & 11,91 & 1 & 3,45 & 3,39 & 15,9 & 79,8 \\
\hline & Restante & 10998,03 & 80 & 11,70 & - & - & - \\
\hline \multirow{5}{*}{ Macho } & Total & 11794,20 & 47 & 15,81 & - & - & - \\
\hline & Entre Pintos & 4661,00 & 11 & 20,59 & 2,17 & 1,4 & 1,7 \\
\hline & Entre Semanas & 4207,28 & 3 & 37,68 & 3,97 & 1,7 & 2,1 \\
\hline & Entre Tratamentos & 39,15 & 1 & $€ ; 25$ & 1,52 & 15,9 & 79,8 \\
\hline & Restante & 2883,77 & 32 & 9,49 & - & - & - \\
\hline
\end{tabular}




\section{4) RESUMO E CONCLUSOES}

A presente experiência fol realizada afim de se constatar a influencia de dois tipos de milho comerciais, com grăos coloridos de amarelo-laranja, como precursores de vitamina A no crescimento de pintos. Um deles, denominado "Cateto", duro, de cor laranja multo forte e outro, chamado "Armour", dente, de coloraçáo amarelo-laranja. Para testemunha fol empregado o milho "Cristal", duro e branco. Uma análise dos pigmentos dos dois tipos de milho com grãos coloridos mostrou que o milho Cateto, com grăos de coloração laranja forte, tem aproximadamente o dóbro de pigmentos, tanto total como quanto a parte ativa em relaçáo à vitamina $A$, quando comparado com o milho dente amarelo-laranja. Três lotes de pintos de 3 semanas foram utilizados, cada um recebendo a mesma raçáo onde varlava sòmente o tipo de milho. Nas três primeiras semanas os três lotes reagiram bem, sem quaisquer diferenças apreciáveis. Após a terceira semana, o lote que recebeu milho branco apresentou uma queda sensivel de peso dos pintos, os quals apresentaram todos os sinais de avitaminose $A$. Os outros dois lotes que receberam raçáo contendo milho de grãos coloridos náo apresentaram sinal de avitaminose A. Os resultados obtidos indicam assim que a) o milho "Armour", dente, de grăos amarelo-laranja, embora possua, em relação ao milho "Cateto", duro, de grãos coloridos de laranja forte, cêrca da metade da quantidáde de pigmentos ativos em relação a formação de vitamina A no organismo animal, é capaz de prevenir a avitaminose, quando empregado em cérca de $70 \%$ da raçáo, b) que a raçáo contendo o milho "Cristal", duro, de grăos brancos, é deficiente, produzindo uma acentuada avitaminose $A$, que deverá ser corrigida, na falta de milho de grãos amarelo-laranja, por alimento verde ou outro allmento fornecedor dessa vitamina e c) que sendo o milho " $\mathrm{Ca}$ teto", mais caro de Cr.\$2,00 a 8,00 por saco de 60 quilos, há vantagem económica no emprégo do milho tipo "Armour" na constituiçăo das misturas para aves.

\section{5) AGRADECIMENTOS}

Registramos nossos agradecimentos ao Dr. Walter Ramos Jardim pelo exame dos animais mortos e ao Dr. Armando Bergamin pela classificação do sexo nos lotes A e C. 


\section{6) ABSTRACT}

Two commercial types of maize', largely used in the State of S. Paulo, Brazil, were tried as source of pró-vitamin A in growing pullets. The amount of pro-vitamin A was found to bo practically doubled in "Cateto", a flint type with deep orange grains when compared with "Armour", a dont type with ycllow o:ange grains. Both "Cateto" and "Armour" proved to be cqually good in preventing avitaminosis $\mathrm{A}$, when used in the same proportion in the ration $(\mathbf{7 0 \%})$. White corn used for comparison produced strong avitaminosis A.

\section{7) BIBLIOGRAFIA}

1) AMaral, F. P. (1942) - A vitamina A. Publicação da Secretaria de Agricultura do Estado de São Paulo. 1942 : 1-113.

2) ANDRES, J. M. (1944) - Análises genetico del color de de endosperma em algunos maices comerciales argentinos. Faculdad de Agronomia y Veterinaria de Buenos Aires. $1: 1-25$.

3) BEARSE, G. E. and M. W. MILLER (1937) The vitamin A requeriments of white Leghorn pullets during the growing period. Poultry Science 16: 34-38.

4) BRIEGER, F. G. (1937) - Tábuas e fórmulas para estatística. Cia. Melhoramentos de São Paulo.

5) GORTNER, R. A. (1938) - Outlines of Blochem'stry. John Wiley \& Sons Inc., New-York.

6) GRANER, E. A. (1943) - Genética da cór amarelo-laranja nas sementes de milho. Revista de Agricultura. 18: 443-445.

7) GRANER, E. A. (1945) - The yellow orange endosperm of maize. The American Naturalist 19: 380-391.

8) GRANER, E. A. (1946) - A importancia do milho amarelo na alimentação dos animais. Revista de Agricultura. 21: 5-7.

9) GRANER, E. A. (1946) - A influência dos pigmentos amarelo-laranja da semente de milho na coloração da gema de ovo de galinha. Anais da Escola Superior de Agricultura "Luin de Queiroz". 3 : 425-436.

10) GRANER, E. A. (1947) Gen Y7, complementar de Y1 e Y3 para a coloraçáo amarelo-laranja da semente de milho. Revista de Agricultura, 22 : 42-54. 
11) HAUGE, S. M. and J. F. TROST (1928) An inheritance study of te distribuition of vitamin $A$ in maize. The Journal of Biological Chemistry. 80 : 107-114.

12) HAUGE, S. M. (1930) - An inheritance study of the distribution of vitamin A in maize. II - Vitamin a in hybrid red maize. The Journal of Biological Chemistry $86: 161-165$.

13) HAUGE, S. M. and J. F. TROST (1930) An inheritance study of the distribution of vitamin $A$ in maize. III. Vitamin A content in relation to yellow endosperm. The Journal of Biological Chemistry. $86: 167-172$.

14) HOLMES, A. D., F. TRIPP and P. A. CAMPBELL (1936) Vitamin A storage by chickens. Poultry Science. 15 : 71-78.

15) JOHNSON, I. J. and E. S. MILLER (1939) Imediate effect of cros pollination on the carotenoid pigments in the endosperm of maize. Cereal Chemistry. 16:88-92.

16) JULL, M. A. (1938) - Poultry Husbandry. Mac Graw-HillBook Co. New York.

17) MANGELSDORF, P. C. and G. S. FRAPS (1931) A direct quantitative relationship betwen vitamin $A$ in corn and the number of gens for yellow pigmentation. Science 73 : 241-242.

18) MEYER, J. R. (1935) - Doenças devidas a falta de vitamina A e D. 0 Biologico. 1 : 113-114.

19) CAMPOS, F. MOURA (1946) - Relatório do $3 .^{\circ}$ ano de estudos sóbre nutrição realizados sob os auspicios dos Fundos Universitários de Pesquisas. São Paulo Médico. 1946 : 249-300.

20) NEIVA, CICERO (1931) Vitaminas e Avitaminose. Revista de Agricultura 6 : 303-310.

21) PALMER, L. S. (1919) - Carotinoid as fat. soluble vitamine. Science 50 : 501-502.

22) PAULSEN, E. F. e E. LIO (1941) - Sobre el contenido en carotinoides de los maices argentinos. Jornadas Agronomicas y Veterinarias de Buenos Aires 1941: 1-13.

23) POLK, H. D. (1940) - White corn shown to be as good as yellow corn in the poltry ration if supplemented with green feed, grazing or cod-liver oll. Mississipi Farm. Research 3 : N.o 3.

24) RANDOLPH, L. F. and D. B. HAND (1938) - Increase in vitamin A activity of corn caused by doubling the number of chromosomes. Science $87: 442-443$.

25) RANDOLPH, L. F. and D. B. HAND (1940) - Relation between carotenoid contents and the number of gens per cell in diploid and tetraploid corn. Journal of Agricultural Research $60: 51-64$. 
26) RECORD, P. R., R. M. BETHKE and O. H. M. WILDER (1937) - The vitamin A requirement of chicks with observations on the comparative efficiency of carotene and vitamin A. Poultry Science $16: 25-33$.

27) STEENBOCK, H. (1919) - White corn vs. yellow corn and a probable relation between the fat soluble vitamine and yellow plant pigments. Science $50: 352-353$.

28) STEENBOCK, H. and P. W. BOUTWELL (1920) - Fat soluble vitamin. III - The comparative nutritive value of white and yellow maizes. Journal of Biological Chemistry $41: 81-96$.

29) ZAPPI, E. V. (1942) - Tratado de Química organica. Tomo 2.", 2.a parte. "El Ateneo", Buenos Aires. 